\title{
DC Network Model Based on VSC-HVDC System
}

\author{
Aleisawee Alsseid ${ }^{1)}$ Abdulrahman Emhemed ${ }^{2)}$ and Alhade Algitta ${ }^{3)}$ \\ 1) 3) College of Electronic Technology - Bani Walid, 38645 Bani Walid, Libya \\ 2) College of Technical Sciences - Bani Walid, Libya, e-mail: abdo_83f@yahoo.com
}

\begin{abstract}
The recent developments in high power rated Voltage Source Converters (VSCs) and the control strategies have resulted in their successful application in HVDC transmission systems, which have become an attractive option for renewable energy applications or for distribution power in large metropolitan areas. $A 1^{153}{ }^{\text {th }}$ order multipleinput multiple-output (MIMO) small-signal model of DC network model based on VSC-HVDC system and controls is developed in state-space form within MATLAB. The optimum values of the controller gains are selected by analyzing the root locus of the analytical model. The developed small-signal detailed models are linearized and implemented in MATLAB. The validity and accuracy of the proposed models are verified against nonlinear PSCAD/ EMTDC and a summary of the model structure and controls is presented in detailed. Confirmation of the effectiveness of optimization gains is done by simulating the modelled system in MATLAB and PSCAD software. There simulation results performed with very good matching is confirmed in the time domain. It is the most detailed model currently available.
\end{abstract}

Keywords - DC network model, voltage source converter, high voltage direct current, DC voltage control, modelling multi terminal VSC HVDC.

\section{INTRODUCTION}

High-Voltage Direct Current (HVDC) technology has been implemented in several places around the world particularly through the last six decades. From the historical point of view, HVDC technology first made its mark in the early subsea cable interconnections of Gotland (1954) and Sardinia (1967), and then for long distance transmission with the Pacific Intertie (1970) and Nelson River (1973) [1]. The application of high voltage (HVDC) transmission for integrating large scale and/or off-shore wind generation systems with the electric grid is attractive in comparison to extra high voltage (EHV) AC transmission systems due to a variety of reasons. HVDC is often the economic means for delivering power over long distances and/or for interconnecting two nonsynchronised $\mathrm{AC}$ networks, which may operate at different frequencies [2]. HVDC has better properties with underground/subsea cable transmission. The increasing use of HVDC transmission has made it as a competitive alternative for AC transmission. Due to social and political resistance, it has become very difficult to construct new overhead lines. Moreover, the overhead lines have significant environmental impact on areas such as land, water, vegetation, and cultural heritage [3]. The voltage source converter based High Voltage Direct Current (VSC-HVDC) technology, also named as HVDC light, is a new invention of HVDC transmission technology which uses self-commutated converters and DC power transmission to interconnect two or more transmission networks. In contrast to the traditional thyristor based HVDC system, the VSC-HVDC system has many features such as: the ability to independently control active and reactive power flows at its terminal; the option to control its terminal bus voltage; and the potential to be connected to a very weak AC system. The main advantages of VSC power transmission are the high controllability and the possibility to make connections in or between networks by low weight extruded cables $[4,5,6]$. Voltage Source Converter based HVDC (VSC-HVDC) has attracted significant interest since the development of high speed, high voltage switches which enable the advantages of VSCHVDC to be exploited commercially [7, 8]. These features make VSC transmission attractive in many applications like the emerging interconnections required by renewable energy sources [9]. With the benefits of the performance of DC links being recognised, interest is growing in extending existing HVDC links into multi-terminal HVDC systems [10]. The availability of $\pm 300 \mathrm{kV}$ DC enables VSC-HVDC system to transmit large amounts of power over long distances. Under restrictions in right-of-way, the VSCHVDC system provides a solution for adding new transmission lines. VSC-HVDC will continue to provide solutions for many challenging issues associated with the modern deregulated power systems such as distributed power generation, power market, feeding remote isolated loads or city centers [11, 12]. VSC also has some disadvantages such as its high power losses and high capital costs compared with conventional HVDC. One of the key features of HVDC is through the opportunity to use underground DC cable which has a great advantage in comparison with overhead lines. The overhead lines change the landscape and constructions of new lines are often met by public resistance. Furthermore, HVDC cables also have lower losses than AC cables. The DC cables are used where overhead lines are unsuitable and due to environmental impacts or land use considerations, such as in high-density urban areas or ecologically sensitive areas. From an environmental point of view, the DC-cable technology has many advantages such as no alternating magnetic field and no risk for oil leakage [13] and is designed to be environmentally friendly [14]. In addition, HVDC cable system does not face the distance limitations or suffer the higher losses of AC cable systems. Extruded HVDC cables are lighter, more flexible, and easier to splice than the massimpregnated, oil-paper cables (MIND) used for conventional HVDC transmission, thus making them more advantageous for land cable applications. The lower cost cable installations made possible by the extruded HVDC cables makes long-distance underground transmission economically feasible for use $[13,14]$. Therefore, HVDC 
systems increase the transmission capacity and system stability very efficiently and assist in prevention of cascading disturbances [15]. A multi-terminal HVDC transmission (M-HVDC-VSC) is an HVDC system with more than two converter stations. M-VSC-HVDC has the possibility of being an attractive alternative to $\mathrm{AC}$ transmission in city centers where underground cable transmission is preferred for safety and environmental reasons [16]. The M-VSC-HVDC system can be used for wind power integration [17], for urban area interconnection [18], the location and isolation of DC faults [19], and for power quality enhancement [20] are reported in the literature. A multiterminal VSC-HVDC system is economically competitive and technically practicable thereby increasing the scope of application of HVDC 1inks. The M-HVDC-VSC transmission is more complex than two terminal HVDC transmission systems. In particular, the control system is more complicated. The central cause of difficulty in modelling of M-VSC-HVDC systems can be review as: Higher order system, Discontinuous and nonlinear nature of signal transfer through converters, Complexity of interaction equations between AC and DC variables, and Frequency conversion through AC-DC converters. However, such studies have been limited and further researches are required to fully exploit M-VSCHVDC system capability. This paper presents a detailed analytical model for a multiterminal HVDC and uses this model to study system control under a range of operating conditions. A d-axis current control and a DC voltage droop control are implemented in the M-VSC-HVDC control system. The dynamics of the system are investigated and compared when the two different schemes are used. The detailed small-signal model of DC network model based on VSC-HVDC system and main control strategies is described and developed in MATLAB. A five terminal MVSC-HVDC was modeled in PSCAD and its operation was investigation. Results obtained from simulation study on an M-VSC-HVDC test system using PSCAD /EMTDC are presented to verify the theoretical analytical model and the proposed control strategies. The M-VSC-HVDC systems in this research are based exclusively on voltage source converters. The model consists of five converters (VSC1VSC5) systems, two sending AC systems (main grid), and three equivalent receiving AC systems. The detail model of the studied network is shown in Fig. 1 in Appendix.

Three terminals (T2, T3, and T4) are connected to different points in the receiving AC grid (large city). Each system has it is own equivalent impedance and ShortCircuit-Ratio. A $\Delta-Y$ transformer is connected with its corresponding impedance to each terminal. Terminal T2 is linked with terminal T1 by DC cable at length of $300 \mathrm{~km}$ the later is connected to receiving end AC2 system. Similarly, terminal T4 is tied with terminal T5 by DC cable at length of $200 \mathrm{~km}$ then connected to receiving end AC3 system. To ensure security of supply and reliability the voltage-source converter at terminal $\mathrm{T} 3$ is arranged in a ring and connected by a DC cable with (T2, T3) at length of $60 \mathrm{~km}$ and $40 \mathrm{~km}$ and (T5-T1) at length of $200 \mathrm{~km}$. VSC multi-terminal HVDC (M-VSC-HVDC) systems, which consist of more than two voltage source converter stations connected together through DC cable to form a DC ring, can increase the flexibility and reliability of transmission systems. In such kind of configuration the faulted section can be isolated from the rest of network without disconnected any converter station. Therefore, power continuously could be supplied to the connected parts of the DC network.

\section{VSC-HVDC CONVERTER CONTROL}

The control strategy of the VSC-HVDC is based upon a simplified mathematical model of the converter connected to the system as depicted in Fig. 2 in Appendix. An extended Park's transformation [21, 22] is used to transform the electrical variables from the $a b c$ reference frame into a synchronous rotating $d q$ reference frame. The advantage of this transformation is that the controllable electrical variables are now DC values. This feature is useful for design, analysis, and for decoupled control of the two AC $d q$ current components. The balanced three-phase system can be transformed into synchronously-rotating orthogonal system by applying Park's transformation. The d-axis of the AC current component contributes to the instantaneous active power $P(t)$ and the q-axis is always in quadrature with it, and represents the instantaneous reactive power $Q(t)$. The overall test system of the VSC-HVDC converter control, using PID control method is depicted in Fig. 2 Appendix. For a multiterminal M-VSC-HVDC one converter is usually used to control the DC voltage. Terminal one (VSCT1) it has the role of providing controlled DC voltage [23, 24], the other terminals control their DC current/power [25]. The proposed control strategy consists of an outer control loops and an inner current control loops. Two inner fast proportional-integrator differential (PID) controllers ensure that the converter currents are bounded under all conditions. In the inner current control loops decoupled current compensation and voltage feed-forward compensation is adopted. The outer controllers include the DC voltage controller, the AC voltage controller and the DC current/power controller. Proportional-Integrator (PI) regulators are implemented in all these outer controllers to eliminate the steady state errors and generate a reference value for the inner. The choice among these different kinds of controllers to provide the reference values of the converter current will depend on the application. The output of the control system $\left(M_{T 1 d}, M_{T 1 q}\right)$, after transformation, into magnitude $\left(M_{m}\right)$ and phase shift $\left(M_{\varphi}\right)$ represent the reference voltages for the pulse-width modulation (PWM). The phase looked loop is used to synchronised the converter firing angles with the AC system. PLL is currently in use in HVDC schemes worldwide and the latest type of PLL is D-Q-Z. The derivation of the PLL linearized model is obtained from [26].

\section{A. AC Voltage Control}

The equations describing the AC circuit linking the VSCT1 and ACT1-M stated in a $d q$ reference frame synchronously rotating with the PCC AC voltage vector $\left(V_{A C T 1}\right)$ are:

$$
\begin{aligned}
L_{A C T 1} \frac{d}{d t} i_{A C T 1 d} & =-v_{A T 1 C d}-R_{T 1} i_{A T 1 d}+\omega L_{T 1} i_{A C T 1 q}+\frac{1}{2} m_{T 1 d} v_{D C} \\
L_{A C T 1} \frac{d}{d t} i_{A C T 1 q} & =-v_{A C T 1 q}-R_{T 1} i_{A C T 1 q}+\omega L_{T 1} i_{A C T 1 d}+\frac{1}{2} m_{T 1 q} v_{D C} \\
P_{A C T 1} & =\frac{3}{2}\left(v_{A C T 1 d} i_{A C T 1 d}+v_{A C T 1 q} i_{A C T 1 q}\right) \\
Q_{A C T 1} & =\frac{3}{2}\left(v_{A C T 1 q} i_{A C T 1 d}-v_{A C T 1 d} i_{A C T 1 q}\right)
\end{aligned}
$$


where $v_{D C}$ is the DC voltage at VSCT1, $R_{T 1}$ represents converter losses, $L_{T 1}$ is transformer leakage inductance, $i_{A C T 1 d}$, and $i_{A C T 1 q}$ are $\mathrm{AC} d q$ current components at ACT1$\mathrm{M}, \omega$ is the frequency of the $\mathrm{AC}$ system and $P_{A C T 1} / Q_{A C T 1}$ is the active and reactive power at the PCC bus. The VSCT1 reference frame is orientated with the $V_{A C T 1}$ voltage vector employing a Phase Locked Loop, such that $v_{A C T 1 q}=0$, and $v_{A C T 1 d}=\left|V_{A C T 1}\right|$. Accordingly, the active and reactive power is controlled by independently controlling the $\mathrm{AC}$ current vector components using modulation control signals $\left(M_{T 1 d}\right.$, $\left.M_{T 1 q}\right)$.

\section{B. DC Voltage Control}

In a VSC based HVDC system, the function of the DC voltage controller is to generate a DC voltage reference of the DC network and controlling the DC voltage to ensure that the power balance is satisfied. The DC voltage controllers adopt PI control to regulate the DC voltage. The output of DC voltage control is the active current $\left(i_{A C T 1 d r e f}\right)$.

\section{Converter Model}

Linking between DC and AC voltages is achieved with the following linearised fundamental converter equations either at VSCT1 or VSCT2 [27]:

$$
\begin{aligned}
& \Delta V_{A C T 1 d}=\frac{1}{2} \stackrel{0}{M}_{T 1 d} \Delta v_{D C T 1}+\frac{1}{2} \stackrel{0}{v}_{D C R} \Delta M_{T 1 d} \\
& \Delta V_{A C T 1 q}=\frac{1}{2} \stackrel{0}{M}_{T 1 q} \Delta v_{D C T 1}+\frac{1}{2}{ }^{0} D C T ! \Delta M_{T 1 q}
\end{aligned}
$$

Linking between $\mathrm{AC}$ and $\mathrm{DC}$ converter currents is similarly achieved by combining fundamental converter voltage equations, with $\mathrm{AC} / \mathrm{DC}$ power balance equations, giving:

$$
\begin{gathered}
\Delta I_{D C T 1}=-\frac{3}{4} \frac{1}{C_{D C T 1}} I_{A C T 1 d} \Delta M_{T 1_{d}}-\frac{3}{4} \frac{1}{C_{D C T 1}} I_{A C T 1 q}^{0} \Delta M_{T 1 q} \\
-\frac{3}{4} \frac{1}{C_{D C T 1}} M_{T 1 d}^{0} \Delta I_{A C T 1 d}-\frac{3}{4} \frac{1}{C_{D C T 1}} M_{T 1 q}^{0} \Delta I_{A C T 1 q}
\end{gathered}
$$

\section{ANALYTICAL MODEL STRUCTURE}

A $153^{\text {rd }}$ order multiple-input multiple-output (MIMO) small-signal model of the VSC-M-HVDC system and controls Fig. 3 Appendix is developed in state-space form within MATLAB. It consists of the following three interlinked sub-system state-space models; $A C$ system model terminal one ( $6^{\text {th }}$ order $), D C$ system model including (DC-cable, Control system, and PLL models), (123 ${ }^{\text {rd }}$ order $)$ and $A C$ system model terminal two ( $6^{\text {th }}$ order). The two terminal VSC-HVDC model which includes AC models (ACT2 and ACT1), DC model and control configurations and the dynamics of the PLL are depicted in Fig. 3 Appendix in the form of block diagrams in order to highlight the interaction between subsystems. It shows the input signals that are entering into the DC model in addition to the output signal that is transferred into $\mathrm{AC}$ systems from the DC system model. The coupling between the respective sub-systems is achieved using selected variables, with $d$ and $q$ denoting the respective vector components. The input and output variables of the sub-systems are conditioned using linking matrices $\left(\mathbf{L}_{D C T 1}, \mathbf{L}_{D C T 2}, \mathbf{P}_{A C T 1}, \mathbf{P}_{A C T 2}\right)$ that are developed using converter fundamental frequency modeling equations (4)-(6) [27]. Additional coupling matrices provide the measured and reference variables required by the respective controllers. The state-space model of VSC-HVDC is written in standard matrix form as:

$$
\begin{aligned}
& \dot{\mathbf{x}}_{s}=\mathbf{A}_{\mathbf{s}} x_{s}+\mathbf{B}_{r e f} u_{r e f} \\
& \mathbf{Y}_{s}=\mathbf{C}_{\mathbf{s}} x_{s}+\mathbf{D}_{r e f} u_{r e f}
\end{aligned}
$$

where the system matrix ( $\left.\mathbf{A}_{\mathbf{s}}\right)$ incorporates the subsystem and linking matrices, and the input/output vectors $\left(\mathbf{u}_{r e f} / \mathbf{Y}_{r e f}\right)$ are:

$$
\begin{gathered}
\dot{\mathbf{X}_{s}}=\left[\begin{array}{ccc}
\mathbf{A}_{D C T 2} & \mathbf{B}_{D C T 2} \mathbf{P}_{A C T 1} \mathbf{C}_{A C T 2 d q} & \mathbf{B}_{D C T 1} \mathbf{P}_{A C T 2} \mathbf{C}_{A C T 1 d q} \\
\mathbf{B}_{A C T 2} \mathbf{L}_{D C T 22} \mathbf{C}_{D C T 2} & \mathbf{A}_{A C d q T 2} & 0 \\
\mathbf{B}_{A C T 1} \mathbf{L}_{D C T 1} \mathbf{C}_{D C T 1} & 0 & \mathbf{A}_{A C d q 11}
\end{array}\right] \\
\mathbf{u}_{\text {ref }}=\left[\begin{array}{c}
V_{D C T \text { 2ref }} \\
V_{A C T \text { 2ref }} \\
V_{A C T 1 \text { ref }} \\
I_{D C T \text { 2ref }}
\end{array}\right], \text { and } \mathbf{Y}_{s}=\left[\begin{array}{c}
V_{A C T 2} \\
V_{D C T 22} \\
V_{A C T 1} \\
I_{D C T 2}
\end{array}\right]
\end{gathered}
$$

\section{CONTROLLER OPTIMIZATION}

\section{A. The Inner Fast Control Loops}

The fastest current controllers can be designed using the differential equations for the converter in the $d-q$ reference frame. The closed loop transfer function of the inner control loop can be derived. The resultant feedback loop is compared with the standard second order system. Using $(1)$, and assuming fast DC voltage control $\left(V_{D C}=\right.$ const $)$, we derive the control signal $M_{d T 1}$ to include the PID control signal $M_{d T 1}$ and decoupling compensation as:

$$
M_{d T 1}=2 \frac{\left(M_{d T 1}^{*}-\omega L_{T 1} I_{A C T 1 q}\right)}{v_{D C}}
$$

Substitution of (10) into (1) and re-arranging gives:

$$
\frac{I_{A C T 1 d}}{M_{d T 1}}=\frac{1}{R_{T 1}+L_{T 1} s}=\frac{k_{1}}{1+T 1 s}
$$

where $k_{1}=1 / R_{T 1}$ and $T_{1}=L_{T 1} / R_{T 1}$. Consequently, a proportional gain $\left(K_{p}\right)$, integral gain $\left(K_{i}\right)$, and differential gain $\left(K_{d}\right.$ with time constant $\left.T_{d}\right)$ controller combines in a feedback loop to give a second-order system:

$$
\frac{i_{A C T 1 d}}{i_{A C r e f T 1 d}}=\frac{\left(K_{p} T_{d} s+k_{d}\right) s+k_{p}}{L_{T 1} T_{d} s^{2}+\left(L_{M d}+L_{L S}+K_{p} T_{d}+k_{d}\right) s+k_{p}}
$$

Considering desired speed of response around $50 \mathrm{~ms}$, and damping ratio $\zeta=0.7$, the parameters $K_{p}, T_{d}$ and $k_{d}$ can be computed. A small integral gain $K_{i}$ is also included to eliminate steady-state error caused by non-zero stator resistance $R_{T 1}$. The $q$-axis controller is designed in same manner using (2). The final controller gains are given in the Appendix.

\section{B. The Outer Controllers}

The response of the system depends upon the interaction of the outer loop controllers with the subsystems so the PI controller parameters cannot be calculated on their own. The model has four outer-loop controllers that monitor the following variables $\left(V_{A C T 1}, V_{D C T 1}, V_{A C T 2}\right.$, and $\left.I_{D C T 2}\right)$. Identification of optimum PI zero location for outer-loop controllers is carried out using the root locus technique with the MATLAB model, where the location of the real poles 
and the damping of the complex poles of the modelled system can be specified. In order to identify the optimized gains three designated zero locations are chosen and their influence on system behavior is investigated. Confirmation of the effectiveness of optimization gains is done by simulating the modelled system in MATLAB and PSCAD.

\section{C.Design of PI Controller}

There are two parameters for each outer-control-loop Proportional gain $K_{p}$ and integral gain $K_{i}$ that can be specified for a desired performance.

$$
G_{P I}(s)=K_{o}\left(K_{P}+K_{i} / s\right)
$$

Or, equivalently,

$$
G_{P I}(s)=K_{o} K_{P} \frac{s+K_{i} / K_{o} K_{P}}{s}=K_{o} K_{P} \frac{s+z}{s}
$$

where the zero $z=-K_{i} / K_{o} K_{p}$ which represent the controller zero and $K_{o}$ is the open-loop gain.

The problem of tuning the controller parameters for a specific desired performance can be described as follows: find out the gains $K_{o}, K_{p}$ and place the zero such that the modelled system satisfies the required performance criteria. The explanation to this task can be established with the aim of the root-locus technique and by using the participation factor. Initially, there are four outer loop controllers that monitor the following variables $\left(V_{A C T 1}, V_{D C T 1}, V_{A C T 2}\right.$, and $\left.I_{D C T 2}\right)$ at both terminals sending and receiving ends.

The design procedure is iterative; therefore the locus in one diagram is dependent on the previous selection in the other loops. To achieve a satisfactory performance of designed controller for both schemes, the zero location for each individual sub-system is investigated for three different values. After the identification of zero location of the modeled system, the performance of the developed controllers can be investigated in the time-domain. The zero is firstly located close to the dominant real pole and then the gain is varied using root locus.
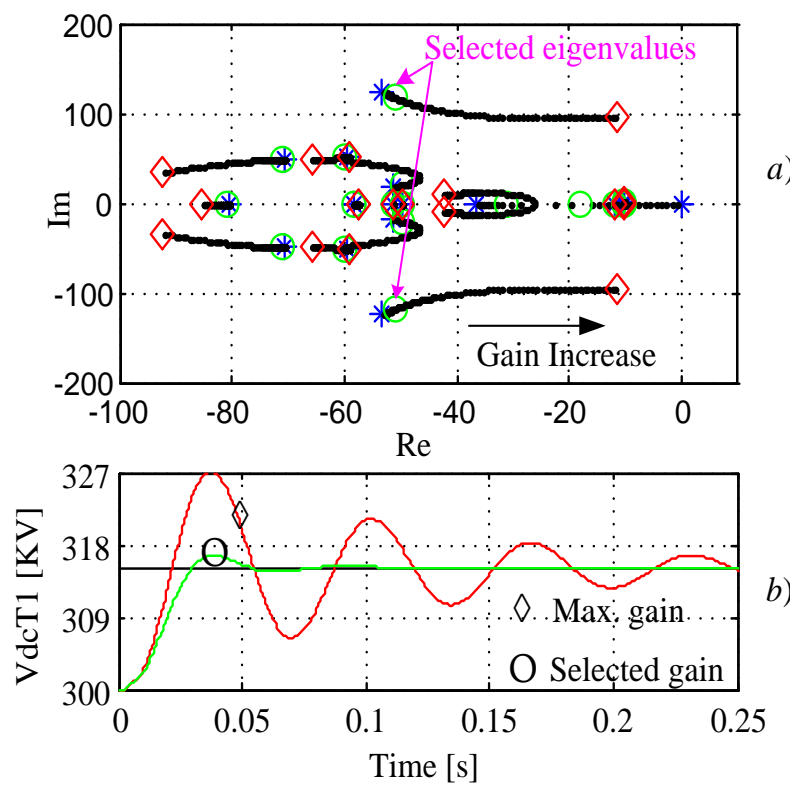

Fig. 4. DC voltage control PI gain $\left(\mathrm{K}_{\mathrm{PdcT} 1}, \mathrm{~K}_{\mathrm{IDCT} 1}\right)$ optimization (SCRT1=10).
Fig. 4a shows the root locus for DC voltage at terminal one, where $K_{o}$ is varied between $[0,0.4]$ as marked by an asterisk $(*)$ and diamond $(\diamond)$ with fixed nominal system configuration.

The design in Fig. 4a is also iterative, since the locus in one figure is dependent on the prior selections in the other loop. It shown that, as the open-loop gain increase the closed loop poles will get closer to the imaginary axis as presented in Fig. 4a. Therefore, the control system performance will have the worse relative stability margins as the gain increased. A 5\% step response is applied on the reference value of $V_{D C T 1}$ in order to evaluate the control system performance as presented in Fig. 4b. Thus, varying $K_{o}$ with keeping all other parameters constant is causing significant changes in speed and quality of system step response. The best performance is clearly confirmed in time domain response with respect to the selected eigenvalues Fig. 4a. Hence the achieved speed of the response is almost below $50 \mathrm{~ms}$.

\section{MODEL VALIDATION}

In order to validate the analytical models against the detailed non-linear PSCAD/EMTDC (PSCAD1) and the simplified non linear PSCAD/EMTDC test system model (PSCAD 2) and to assess their accuracy, their performance is compared by conducting small-signal step tests in the detailed time-domain simulations on each of the analytical model external inputs of both sending and receiving ends. Fig. 5 shows the comparison between the linear smallsignal model and PSCAD models. A set of figures are presented for the applied step input in order to confirm the validity of the modeling system. Fig. $5 \mathrm{a}-5 \mathrm{~d}$ show the response signals of the following variables at VSCT1 $V_{A C T 1 r e f}, V_{D C O T 1}, I_{d T 1}, I_{q T 1}$ whereas Fig. $5 \mathrm{e}-5 \mathrm{~h}$ are illustrating the response signals of the following variables at VSCT2 $V_{A C 0 T 2}, I_{D C O T 2}, I_{d T 2}, I_{q T 2}$ respectively. The detailed PSCAD1 model responses exhibit greater noise content, and there is pronounced non-linear behaviour. The high noise content is attributed to the low switching frequency and also as a significance of the optimized value for the DC capacitors. However with use of the simplified PSCAD model it can be clearly appreciated from Fig. 5 that, despite significant linearization and continuous power converter system modelling, the analytical model demonstrates very good small signal accuracy. The results for a step change in AC voltage reference $V_{A C r e f T 1}$ are shown in Fig. 5a. The behavior of test system where the step change is applied is almost identical for both models. The reaction of the DC voltage to the applied step change is shown in Figure $5 \mathrm{~b}$. There is a very good correspondence between the models. The $d q$-axis current components at terminal one are shown in Fig. $5 c-5 d$. The response matching in those figures were also confirmed and found to be very good agreement. Fig. $5 \mathrm{e}$ illustrated the corresponding dynamic interaction on the AC voltage at terminal two $V_{A C T 2}$. As it is illustrated in Fig. 5f the DC current controller behaves well, tracking the reference with accuracy, very good agreement is achieved. The $d q$-axis current components at terminal two are shown in Fig. 5f and 5h the same conclusion is observed as obtained from Fig. 5c and 5d. Accurate and fast regulation of monitored variables $V_{A C r e f T 2}, V_{D C O T 2}, V_{A C 0 T 2}$, and $I_{D C O T 2}$ is achieved in Fig. 5a, 5b, 5e and $5 \mathrm{f}$ respectively and the multivariable properties of the system (control interactions) are also modeled accurately. 

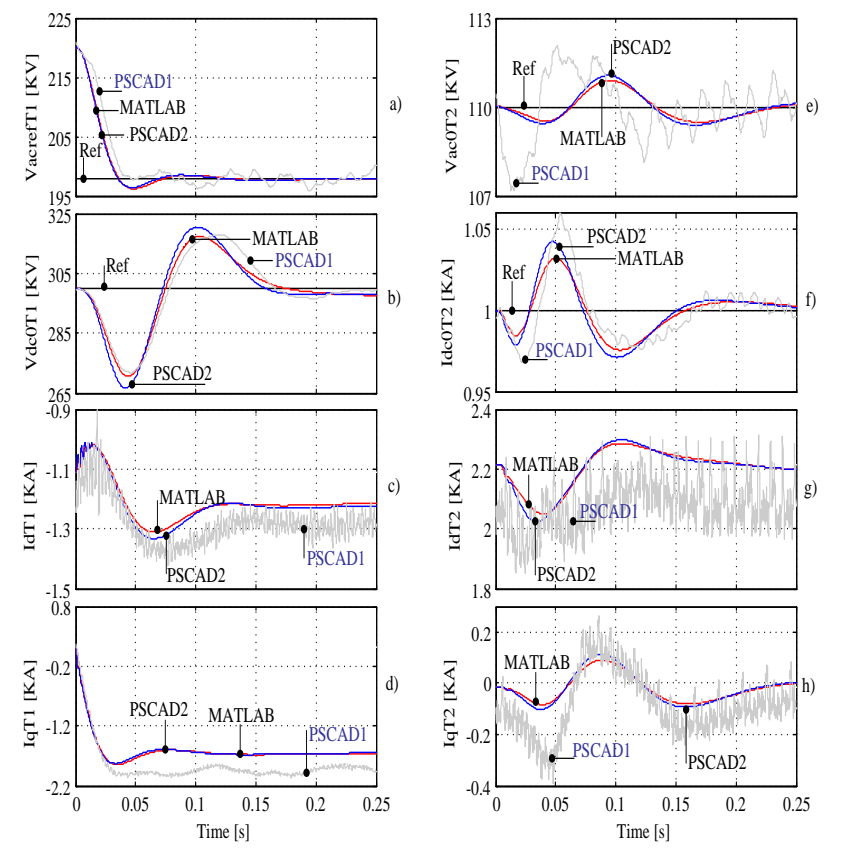

Fig. 5. Analytical model verification strategy 1 , following a $-10 \%$ AC voltage reference step change $\left(V_{A C T 1 r e f}\right)$ :

a ) AC voltage $\left(V_{A C T 1 \text { ref }}\right)$, b) DC voltage $\left(V_{D C T 1}\right)$,

c ) Direct current $\left(I_{A C T 1 d}\right)$, d) Quadrature current $\left(I_{A C T 1 q}\right)$, e ) AC voltage $\left(V_{A C T 2}\right)$, f) DC current $\left(I_{D C T 2}\right)$,

g ) Direct current $\left.\left(I_{A C T 2 d}\right), \mathrm{h}\right)$ Quadrature current $\left(I_{A C T 2 q}\right)$.

\section{CONCLUSIONS}

A test system of DC grid network is developed in PSCAD. A detailed and accurate analytical model of DC grid is presented in this paper. The dynamic analytical statespace model is built of subsystems to enable model application to a wide range of MIMO system dynamics investigation. The derived detailed models are linearized and implemented in MATLAB. The validity and accuracy of the proposed models are verified against non linear PSCAD simulations, and very good matching is confirmed in the time domain. It is the most detailed model currently available.

\section{ACKNOWLEDGEMENTS}

The author gratefully acknowledge support from professor D. Jovcic, School of Engineering, University of Aberdeen, Aberdeen.UK.

\section{REFERENCES}

[1] Prabha Kundur, Power System Stability and Control. McGraw-Hill, 1994.

[2] X.-P. Zhang, "Comprehensive modeling of the unified power flow controller for power system control," Electrical Engineering, vol. 88, no. 4, pp. 241-246, April 2006 https://doi.org/10.1007/s00202-004-0280-0

[3] Stijn Cole, Dirk Van, Leonardo Meeus, and Ronnie Belmans, "Technical development of the Future Transmission Grid", in Power Engineering Society General Meeting, 2007. 24-28 June 2007, pp. 16.

[4] B. Jacobson, Y. J Iang-Hafner, P. Rey, and G. Aspund, "HVDC With Voltage Source Convectors and Extruded Cables for up to $\pm 300 \mathrm{kV}$ and $1000 \mathrm{MW}, "$ B4-105, CIGRE 2006.

[5] G. Asplund, K. Eriksson, and H. Jiang, "DC transmission based on voltage source converters," in Cigre Conference 14-302, France, 1998.
[6] N. Flourentzou, V. G. Agelidis, and G. D. Demetriades, "VSC-based HVDC power transmission systems: An overview," IEEE Trans. Power Electronics, vol. 24, no. 3, pp. 592-602, 2009.

https://doi.org/10.1109/TPEL.2008.2008441

[7] K. Eriksson, "HVDC light and development of voltage source converters," ABB review, 2002.

[8] F. Schettler, H. Huang, and N. Christl, "HVDC transmission using voltage sourced converters - Design and Applications," in IEEE summer power meeting 2000, Seattle, July 2000.

[9] Lars Weimers, "HVDC Light - a new technology for a better environment," IEEE Power Engineering Review, pp. 19-20, August 1998. https://doi.org/10.1109/MPER.1998.691411

[10]P. C. S. Krishnayya, S. Lefebvre, V. K. Sood, and N. J. Balu, "Simulator study of multiterminal HVDC system with small parallel tap and weak AC systems", IEEE Trans. on Power Apparatus and Systems, no. 10, pp 3125-3132, October 1984. https://doi.org/10.1109/TPAS.1984.318334

[11] Mojtaba Noroozian, Abdel-Aty Edrise, David Kidd, and Abrt J.F.Keri, "The Potential Use of Voltage-Sourced Convector-Based Back-to-Back Tie in Load Restorations," IEEE Trans. On Power Delivery, vol.18, no.4, pp. 1416-1421, October 2003. https://doi.org/10.1109/TPWRD.2003.817777

[12]K. R. Padiyar, Nagesh Prabhu, "Modeling, Control design and Analysis of VSC based HVDC Transmission Systems", in International Conference on Power System TechnologyPOWERCON 2004, 21-24 November 2004. Singapore, pp.13511355.

[13] L. Weimers, "New markets need new technology," in Proc. of 2000 International Conference on Power System Technology, vol. 2, Perth, Australia, pp. 873-877, December 2000.

[14]K. Eriksson, "Operational experience of HVDC Light," in Seventh International Conference on AC-DC Power Transmission, London, U.K., November 2001. https://doi.org/10.1049/cp:20010543

[15] M. Bahrman and B. Johnson, "The ABCs of HVDC Transmission Technology," IEEE Power Energy Magazine, Vol. 5, pp. 32-44, March/April 2007. https://doi.org/10.1109/MPAE.2007.329194

[16]Xiao-Ping Zhang, "Multi-terminal voltage-sourced converter-based HVDC models for power flow analysis," IEEE Transactions on Power Systems, vol. 19, issue 4, pp.1877-1884, Nov. 2004. https://doi.org/10.1109/TPWRS.2004.836250

[17] W. Lu and B.-T. Ooi, "Optimal acquisition and aggregation of offshore wind power by multiterminal voltage-source HVDC," IEEE Trans. Power Delivery, vol. 18, no. 1, pp. 201-206, January 2003. https://doi.org/10.1109/TPWRD.2002.803826

[18]H. Jiang and A. Ekstrom, "Multiterminal HVDC systems in urban areas of large cities," IEEE Trans. Power Delivery, vol. 13, no. 4, pp. 1278-1284, October 1998. https://doi.org/10.1109/61.714496

[19]L. Tang and B. Ooi, "Location and Isolating DC Faults in Multiterminal DC Systems," IEEE Trans. Power Delivery, vol. 22, no. 3, pp. 1877-1884, 2007. https://doi.org/10.1109/TPWRD.2007.899276

[20] W. Lu and B. Ooi, "Premium quality power park based on multiterminal HVDC," IEEE Trans. Power Delivery, vol. 20, no. 2, pp. 978-983, April 2005. https://doi.org/10.1109/TPWRD.2004.838633

[21]I. Papic, P. Zunko, D. Povh, and M. Weinhold, "Basic control of unified power flow controller," IEEE Trans. Power System, vol. 12, pp. 1734-1739, Nov. 1997. https://doi.org/10.1109/59.627884

[22] C. Schauder and M. Mehta, "Vector analysis and control of advanced static VAR compensators," IEE Proceedings - Generation, Transmission and Distribution, 140(4), July 1993. https://doi.org/10.1049/ip-c.1993.0044

[23] Weixing Lu and Boon-Teck Ooi, "DC Overvoltage control during loss of converter in multi-terminal voltage-source converter-based HVDC (M-VSC-HVDC)," IEEE Transactions on Power Delivery, vol. 18, issue 3, pp.915-920, July 2003. https://doi.org/10.1109/TPWRD.2003.813888

[24] B R Andersen, L Xu, and K T G Wong, "Topologies for VSC transmission," Seventh International Conference on AC-DC Power Transmission (IEE Conf. Pub. No.485). IEE, 2001 London, UK, pp. 298-304. https://doi.org/10.1049/cp:20010559 
[25]D. Jovcic, "Interconnecting Offshore Wind Farms Using Multiterminal VSC-based HVDC," IEEE PES general meeting, Montreal, pp. 1-7, June 2006.

https://doi.org/10.1109/PES.2006.1709326

[26]D. Jovcic, Control of High Voltage DC and Flexible $A C$ Transmission Systems. PhD Thesis, University of Auckland, New Zealand, December 1999.
[27]D. Jovcic, N. Pahalawaththa, and M. Zavahir, "Analytical modelling of HVDC-HVAC interactions," IEEE Trans. Power Del., vol. 14, no. 2, pp. 506-511, Apr. 1999. https://doi.org/10.1109/61.754095

\section{APPENDIX}

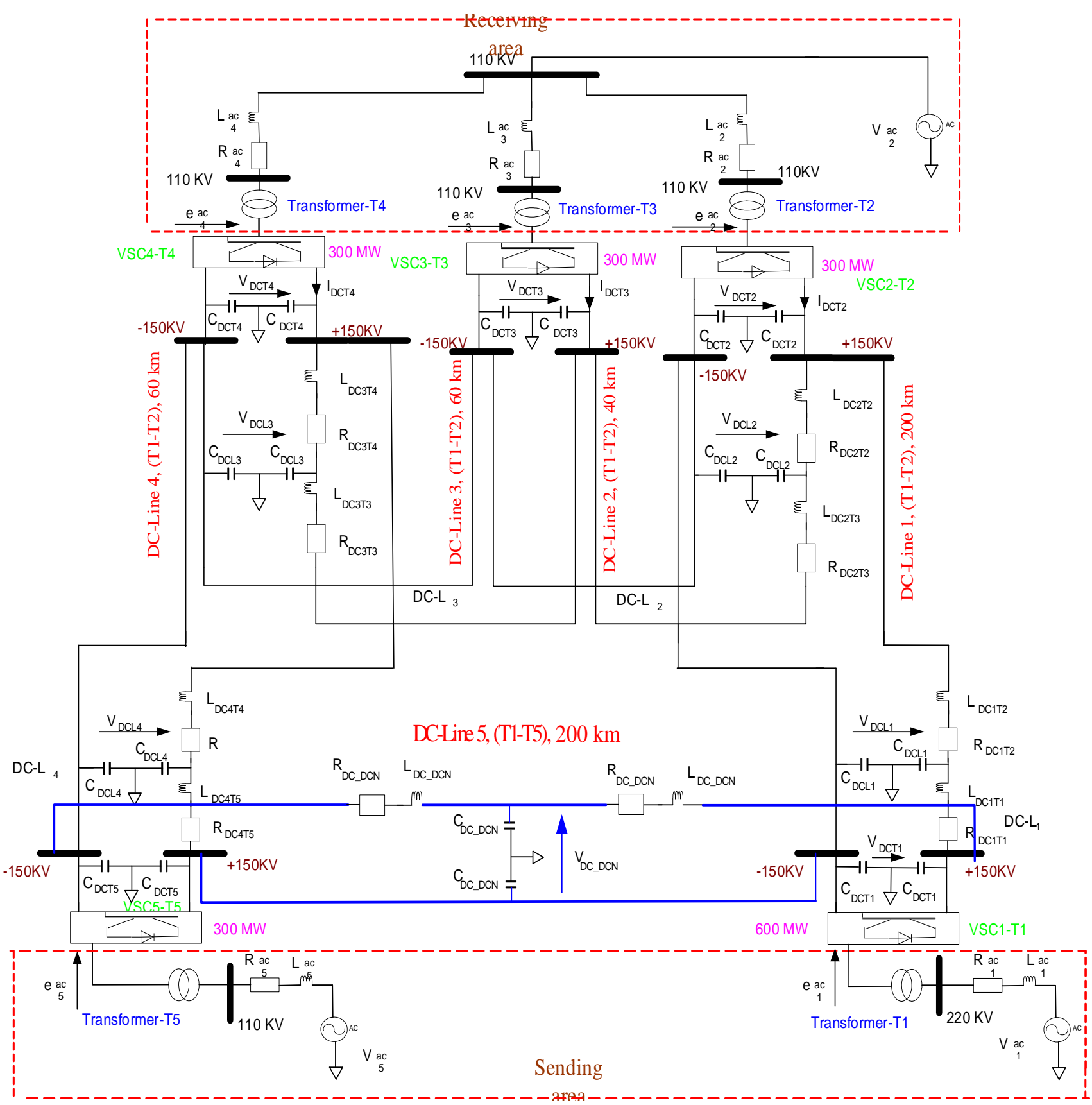

Fig. 1. Detailed model of studied network. 


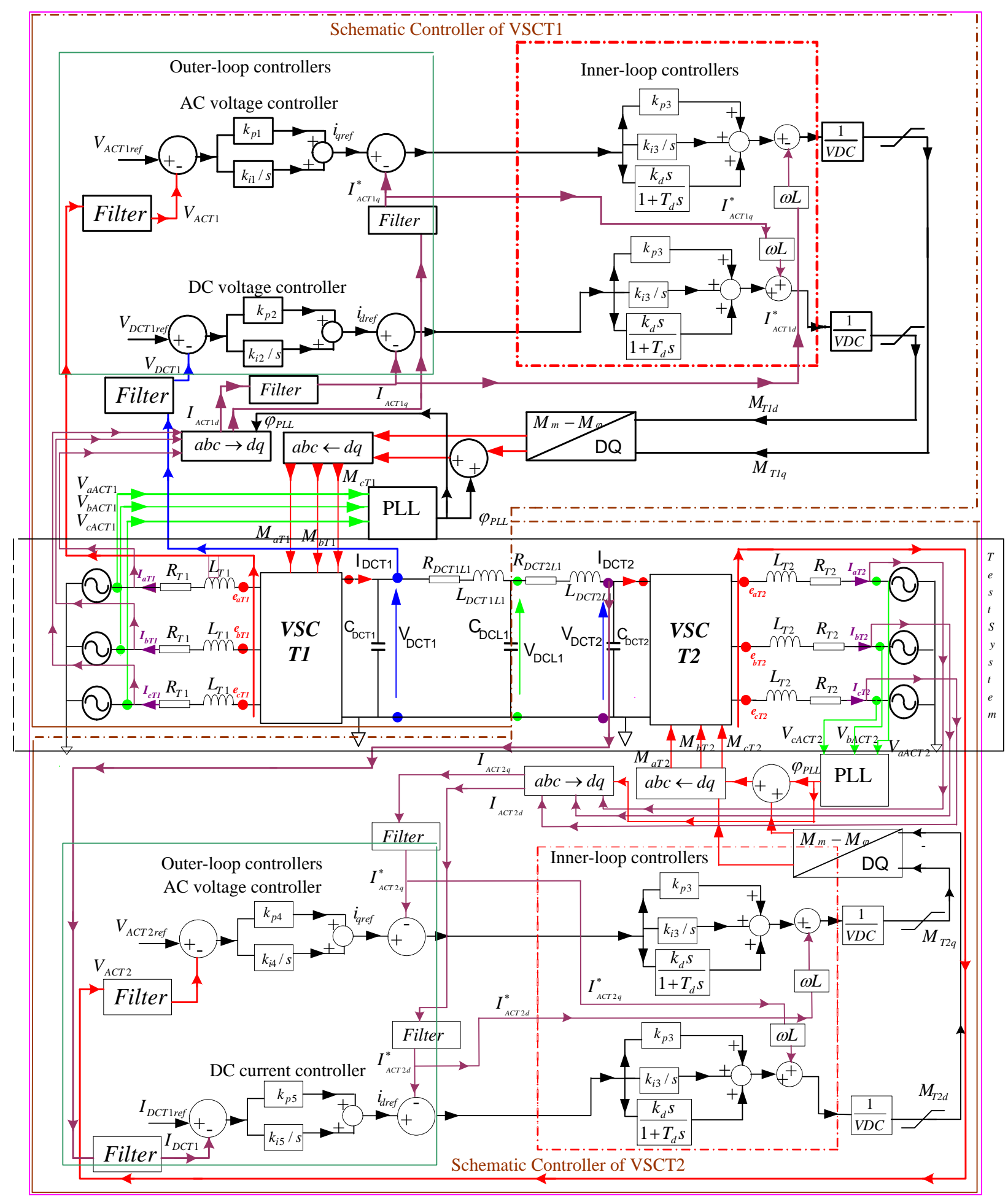

Fig. 2. Diagram circuit and overall control block of two stations of VSC-HVDC model. 


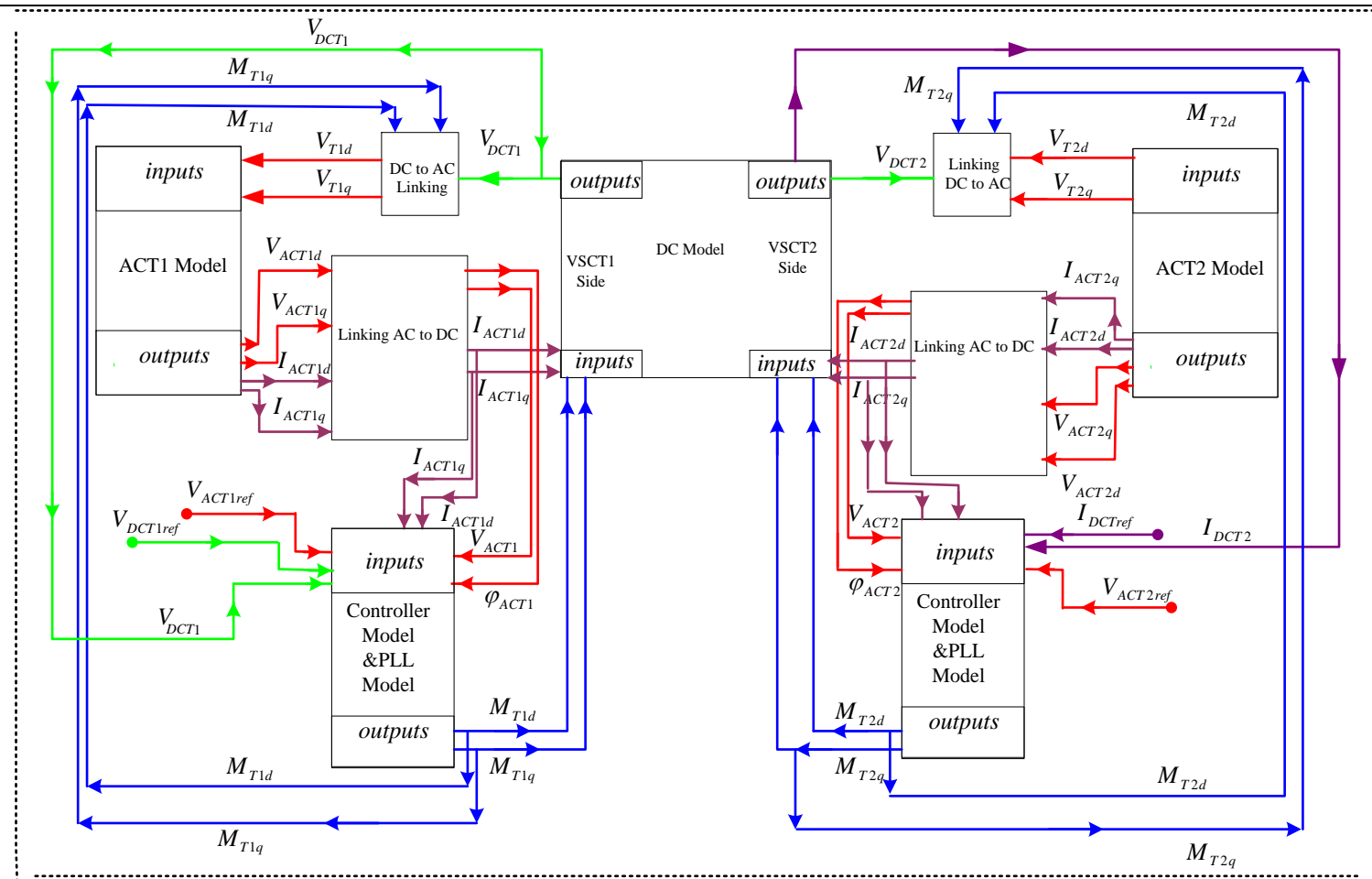

Fig. 3. Schematic diagram of linking subsystems models. 